\title{
The Development and Application of CISMOD 1.0, a New Computerized Tool for Designing Wildlife Rainwater Cisterns
}

\author{
Ariel Ortega ${ }^{1}$, Dave Menicucci ${ }^{12^{*}}$ \\ ${ }^{1}$ University of NM, Albuquerque, NM, USA \\ ${ }^{2}$ Sandia National Labs (retired), Albuquerque, NM, USA \\ Email: *dfmenic@unm.edu, dmenicucci1@comcast.net
}

How to cite this paper: Ortega, A. and Menicucci, D. (2021) The Development and Application of CISMOD 1.0, a New Computerized Tool for Designing Wildlife Rainwater Cisterns. Computational Water, Energy, and Environmental Engineering, 10, 71-81.

https://doi.org/10.4236/cweee.2021.102005

Received: March 19, 2021

Accepted: April 23, 2021

Published: April 26, 2021

Copyright $\odot 2021$ by author(s) and Scientific Research Publishing Inc. This work is licensed under the Creative Commons Attribution International License (CC BY 4.0).

http://creativecommons.org/licenses/by/4.0/

\section{(c) (i) Open Access}

\begin{abstract}
This article reports on a case study of the research and development of a new tool to assist in the design of rainwater cisterns. A rainwater cistern is a way to improve wildlife habitat because it can be situated in locations that do not have natural water sources, such as streams or wells that can supply water for storage. However, the design and sizing of such a system can be challenging because a number of constantly varying factors must be considered, such as changing precipitation patterns, the evaporative losses from the cistern and animal water consumption. No standardized sizing methodology currently exists for designing wildlife rainwater cisterns. In this article we present a new method for assisting in optimally sizing a rainwater cistern. We discuss how we implemented the quantitative portion of this methodology into a new Ex$\mathrm{cel}^{\circledR}$ model called CISMOD, which we configured for general use by wildlife professionals. We describe the methodology for designing a rainwater cistern based on standard engineering techniques. We then present and discuss our experience in applying the model to design two rainwater cisterns in an area of the Jemez Mountains in northern New Mexico, USA. The CISMOD model and a user manual are available at no cost for wildlife professionals.
\end{abstract}

\section{Keywords}

Cistern, Wildlife, Design, Sizing, Construction

\section{Introduction}

This article reports on a case study of the development of a new tool to assist in the development of rainwater cisterns. Water is an important factor to improve 
habitat for wildlife, especially in dry areas of the U.S. Pumping water from a drilled well and damming of springs and creeks are cost-effective methods for serving wildlife watering ponds and stocking tanks. However, some situations call for a wildlife watering tank in areas where these permanent sources of water are not available. A cistern with a rainwater collector can provide water in those areas.

Designing a rainwater cistern becomes a complex endeavor when the various factors that affect the performance of the cistern are considered. Fundamentally, a rainwater cistern (hereafter "cistern") consists of a rainwater collector and a tank or pond to store the water. The rainwater collector, typically a constructed watershed resembling a roof, must be sized appropriately relative to the size of the tank.

The size of the cistern itself is important. Too small a cistern relative to the size of the collector would be unable to capture and hold all of the water collected; much water would be wasted. If a drought were to occur, a smaller tank would have the insufficient volume to remain wetted during critical periods. On the other hand, too large a cistern relative to the collector is expensive to install and would never be fully wetted. A tank or pond that is less than fully wetted produces more exposed surface to volume and evaporation becomes a critical loss factor. Therefore, finding the optimal size of the collector relative to the cistern volume is the main challenge and was the focus of the work that we present here.

While rain is the principal driver in the cistern system, evaporation losses from the water surface, especially in open tanks and ponds, are also important to consider, especially in the warm parts of the year. Wind can accelerate evaporation. Of course, water consumption by animals is also an important variable that affects design.

A designer of a rainwater cistern in a remote area is faced with these and other variables that must be considered simultaneously in order to produce a design that is close to an optimal size. The principal variables include rainwater, water consumption and evaporation, which are affected by air temperature and wind. These factors vary constantly, vary not only daily but seasonally. There are several things happening simultaneously. The collector produces a certain amount of water that flows into the cistern, some of which is consumed by the animals and some is lost to evaporation. Some days it rains and some days are dry. Some days are hot and others cold. It is windy on some days and calm on others. Some days more animals drink than on other days. And so on.

To an unseasoned designer, the task appears to be nearly impossible because of the multitude of variables involved. Many simply surrender to the complexity and guess at the size, build it and hope for the best, which in engineering is called the "poke and hope method". But this often results in a poorly performing cistern that will require field retrofits later. Ertas and Jones and Hyman describe the basic engineering methodology [1] [2].

There have been few published efforts to address the issue of optimally sizing 
rainwater cistern for wildlife applications. For example, Pelak and Porporato present a complex method of optimizing cisterns in residential applications, but they leave the reader to implement the techniques into a working model or application for wildlife [3]. Basinger, Montalto and Lall discuss methods for determining the reliability of residential systems [4]. We believe the level of complexity of these techniques is unnecessary to obtain an optimal design for wildlife cisterns. While some of the general methods described by these authors are implemented into CISMOD, the majority of the model was developed from fundamental engineering principles and designed for the specific application of sizing rainwater cisterns for wildlife applications.

For this project we applied the standard engineering design to this design problem. We started by assessing the various constituent subsystems and assessing how these subsystems interact with each other within timesteps that are small enough for the variables to be considered stable. For our application we chose a timestep of one day. Therefore, our weather inputs for each day are daily averages or in the case of precipitation, daily totals.

To model the cistern's performance for each day we need to know how much water was in the tank from the previous day, how much rain was received that day, the daily average temperature, humidity and wind speed and how much water was consumed by animals. From these variables we can then compute the amount of water in the cistern at the end of the day by subtracting the amount of water lost from the amount of water gathered. These computations can be facilitated by integrating them into a computer model. If the model is applied to every day of the year, the projected performance of the cistern can be charted throughout the year showing the daily volume of water in the tank. This can provide information to the designer as to how the cistern system might perform at critical times, such as when animals are known to be seasonally migrating through the area.

However, simply having a model that accurately performs the daily computations is not the final solution because the inputs are highly variable. One year is dry, another is wet; one year is exceptionally hot while another is cool; etc. A single run of the model for a specific set of daily conditions does little more than inform about the cistern's performance in those specific conditions. In fact, the proper design of a cistern is one that performs adequately in the range of expected conditions. CISMOD facilitates this process of investigation.

Gathering the inputs, especially historical weather data, is often a challenge. For the purposes of the following discussion on how the model was developed and applied we assumed that we had access to reasonably accurate weather data that we could input into the model. We will address this data issue later when we discuss our application. The CISMOD user manual contains a detailed section on the issue of available weather data and provides some other resources for the cistern designer.

A design model such as CISMOD is not intended to be used as a single-run decision tool. Instead, it provides insight into how a cistern with a certain confi- 
guration might operate under specific environmental conditions. The model allows the designer to do two important comparisons:

1) Estimating the performance of a specific cistern design under different environmental conditions.

2) Estimating the performance of different cistern designs under the same environmental conditions.

Thus, the designer's own judgment is still a critical factor in the design. For example, the designer might wish to assess the performance of a cistern in years that are dry, wet and normal. After seeing the results, the designer may modify the system design, such as increasing the size of the collector but holding the tank volume constant, and then assess its performance in the same three years. Since a run of the model is quick and easy, it effectively provides the designer insight into the performance of the cistern system and allows the design to be more optimally tailored to the application. No such sizing models such as CISMOD currently exist for sizing wildlife rainwater cisterns.

\section{Materials and Methods}

This work was spurred by a new initiative by the New Mexico Department of Game \& Fish designed to encourage private landowners to improve habitat for elk and other ungulates. Author Menicucci's public press article describes the program and how it influenced this technical work [5].

We chose two test sites for two cisterns, one on a ranch owned by author Menicucci about three kilometers south of the Valles Caldera National Preserve at about 2700 meters of elevation and the other at Menicucci's cabin, about one kilometer west of the preserve at about 2400 meters of elevation.

Both of these properties are in the Jemez Mountains in northern New Mexico, USA, in the area around the Valles Caldera National Preserve. This mountain area is a monsoon-influenced warm-summer humid continental climate, Dwb in the Koppen climate classification system. Wikipedia provides a thorough explanation of the Koppen system [6].

In the area long, cold winters with absolute low temperatures as low as $-30^{\circ} \mathrm{C}$ in January begin as early as late September and end as late as late May. Annual snowfall totals can extend to five meters. Summer high temperatures are warm and humid but rarely exceed $30^{\circ} \mathrm{C}$. Rainfall typically ranges around 75 centimeters per year in the lower areas to over 100 centimeters in the upper ones, although many dry years would see only about $20 \%$ of these totals. About half of the annual precipitation falls between July and September with thunderstorms that can drop 10 centimeters of rain in a single storm. These potentially extreme conditions present a design challenge. The area is replete with wildlife ranging from elk, deer and bighorns as well as many predators, such as cats and bears.

In this section we describe how we developed and applied CISMOD to design the cisterns on the two properties. However, to avoid the complication of describing complex engineering equations in this paper, we present a narrative 
overview of them with specific references for those readers who are interested in the details. The CISMOD model itself is editable and the user may examine the equations and computations directly therein.

The methodology we employed to apply CIEMOD involved five steps.

- Develop an Excel ${ }^{\oplus}$-based cistern simulation model called CISMOD.

- Collect data to input to CISMOD.

- Run CISMOD to optimally size the cistern.

- Install the cistern.

- Monitor cistern's performances and compare to model predictions.

CISMOD is designed to simulate the annual performance of a cistern by estimating the daily performance of the system and then tabulating and graphically summarizing the daily results over a year. Annual summary statistics are also presented. The model requires user-supplied assumptions, including the cistern's capacity, the area of exposed water, the cistern's volume on the initial day of the simulation period, and the collector area. The daily inputs include average animal water consumption, temperature, wind speed, relative humidity and precipitation. For every daily simulation period CISMOD computes the water gained from precipitation and subtracts the water lost to animal consumption and evaporation. The result is the volume of water remaining in the cistern for the next day in the simulation.

Most of the calculations are simple arithmetic but the evaporative loss calculations are more complex, based on temperature, humidity, windspeed, and exposed surface area. Water lost to evaporation is not insignificant. For example, a 1900 -liter cistern with 1.1 square meters of exposed water area located in an area with a temperature of $30^{\circ} \mathrm{C}$, a relative humidity of $20 \%$, and a wind speed of 5 meters/sec would lose about 23 liters of water per day.

To estimate the daily loss of water due to evaporation we used the "Evaporation from Surface Water" equation described on The Engineering ToolBox website [7]. This is a standard engineering tool that is well vetted through use and is generally free of errors.

There is a limitation to this equation as we have applied it. It is not precisely accurate when the surface of the water is frozen. Although there is sublimation from the ice surface, the model ignores it and assumes that the water evaporates. While this may seem to be a serious limitation, in fact it is relatively inconsequential. First, the cistern is inoperable when it is frozen. Therefore, computations as to water lost to evaporation are superfluous. Second, the model computes the evaporation losses assuming that the water is liquid. However, the estimates of water lost through evaporation are roughly comparable to the losses in the same body of water due to sublimation.

In the model's output graphics, we designate those days where the tank may be frozen, although in many cases in late winter and spring, the cistern may only be glazed over for a few hours in the mornings. In these cases, the estimates of water lost due to sublimation are similar to those losses via evaporation, and the total amount lost is small. The inputs to the evaporation equation include the 
wind velocity, ambient air temperature, humidity, and the surface area of the water in the tank that is exposed to the air.

The collector equation computes the amount of water that falls onto the surface and is collected in the cistern. We added a factor for water gathering efficiency because not all the water that falls on the collector will be captured. Some is lost by splashing, leaks in the piping, and initial evaporation off a hot collector surface. The user can estimate the approximate efficiency to use as an input based on the quality of the collector system. We account for the rainwater that falls directly onto the cistern's water surface. The model also estimates the installed cost of the project. The inputs include the costs for various materials, such as lumber, roofing materials, cisterns, piping, etc.

After integrating the equations into the Excel model, we tested it rigorously. After removing a number of bugs and we were convinced of its mathematical integrity, we moved on to apply CISMOD to our cistern designs.

We collected weather data for inputs through a variety of sources. For the ranch site our best source of precipitation and temperature data was from a neighbor, a retired Los Alamos National Lab scientist with a weather station located about 500 meters from the site of the cistern. He had rigorously hand-recorded data for over 20 years. However, in the winter months his precipitation records were his best estimates of the precipitated water based on melted snowfall, which he measured with a ruler. We quantified his data from 2004 to 2018.

Our methodology also required daily inputs for average relative humidity and wind speed, which were not available from the neighbor. Thus, we sought out other sources. Professional quality weather data, including precipitation, wind speed, temperature and relative humidity, are recorded at various sites on the Valles Caldera National Preserve. We selected the Headquarters Valle Grande site located five kilometers from the ranch site. We downloaded hourly data from 2004 to 2018 from the Western Regional Climate Center [8]. We converted these data to daily averages using Excel ${ }^{-}$. The addition of these humidity and wind data gave us a complete set of daily weather data for our model. By perusing the records from these two sources we selected two test years. One, 2018, was dry, our worst case. The other, 2015, was wet and was our best case.

Near the cabin site, we used data from the Horseshoe Springs La Cueva weather station located about one kilometer away that is maintained by a University of Arizona Biology professor emeritus who lives in the area. The weather data were archived through the Weather Underground Service [9].

We used visual data from trail cameras to estimate the number and types of animals that might use the cistern. The cameras were placed on the properties where the cisterns were to be located. From an analysis of the photos, we estimated that there would be on average three deer and one elk visiting the cistern every day. We consolidated smaller animals into one miscellaneous category, assuming that 10 of these animals would visit daily.

We assumed that at the ranch the animal visitations during the months of 
December through February were about 33\% of that in the other months. At the cabin site we used the photos to estimate the same mixture of animals with the same monthly visitation patterns at half the rate of ranch visits.

According to a local ranching and wildlife expert, Dennis Trujillo, a 300-kilogram bull elk might drink about 40 liters per day while grazing in the Jemez Mountains [10]. According to Trujillo, smaller animals, such as deer or bighorn sheep, will consume proportionally less water based on their weight. We used these consumption numbers for the animals that we assumed would be visiting.

As a note to some readers who are experts on ungulates, we recognize that more precise data on watering might be available, but given the uncertainty of all the inputs relative to the overall design and understanding that the model provides insight rather than a specific answer, we believed that this approach would suffice for the project. Another CISMOD user may enter whatever numbers are deemed appropriate.

\section{Results}

Our approach was to run CISMOD using various sizes of collectors and cisterns and compare the performance of each modelled system in the wet and dry years we selected for our test cases. Essentially, we were seeking insight on the performance of different designs in various weather years. The most important criterion was that the cisterns remain essentially wetted for most of the year; the only exception being the deep winter months when it freezes over. The winters in the area are quite harsh and few animals are in the area at that time.

We only considered cistern sizes consistent with those available from Rainmaker Wildlife Products in Washington State: 795 liters (210 gallons), 1893 liters (500 gallons), and 3786 liters (1000 gallons) [11]. These cisterns are partially covered to allow animals access to the water while limiting evaporation, which we will show is an important factor in designing a rainwater cistern.

For the ranch system we considered three collector sizes: 10, 20 and 30 square meters. We planned to use a 28 square meter roof watershed from the cabin as a rainwater collector.

All model runs were completed using the assumptions for animal use as noted earlier. For the ranch system we ran CISMOD for all of the combinations of the three cistern sizes, three collector sizes and our best- and worst-case years, a total of 18 runs. For the cabin, we did similar runs using the appropriate data and the one watershed from the roof. Thus, we only examined three cistern sizes in both of our test years, a total of six runs.

After each of the 18 runs we examined the output of the model relative to our goals of a fully wetted cistern year-round. For example, when we ran the model using a 10 square meter collector, we found that the cistern would remain fully wetted in our wet year but went dry at critical times in drier parts of the year, especially in a very dry year. A 30 square meter collector produced too much water. We also examined the impact that different size cisterns in various appli- 
cations had on the overall performance of the system. In some cases, we did some additional runs to refine our understanding, such as examining a 25 square meter collector in some applications. During the iterations of CISMOD, we considered the cost of the collector, including the difficulty of hand carrying the materials and tools into a remote and rugged area of the ranch.

We also examined how much the animal visitation assumptions affected our design by examining some runs with $10 \%$ more animals than our assumption and those with $10 \%$ fewer ones. We found that while the number of animals visiting had an impact on the design; the overwhelmingly important variables are rainfall and the evaporation, especially in the warmer parts of the year. CISMOD made these comparisons relatively easy.

This series of model runs was effectively performance trials for the cistern of various sizes in our two test different years (our wet year and our dry one). After analyzing the set of 18 simulations along with some supplementary runs, we selected the 1893-liter cistern for both the cabin and ranch locations because they appeared to have sufficient capacity to remain wetted in our dry year. We selected 20 square meters as the optimally sized collector for the ranch cistern.

Figure 1 and Figure 2 show the performance for 2015 and 2018 respectively using an 1893-liter cistern and 20 square meters of water collecting surface at the ranch. The graphs are taken from CISMOD. The numbers on the abscissa are the Julian dates. The daily precipitation totals are shown with blue bars and the water remaining in the cistern at the end of each day is shown with an orange line. The gray dots on the line indicate the days when the cistern might be frozen. Note that in the simulation for the dry year (2018), the cistern nearly dries out with a few days showing no water, but quickly gained enough water to serve animals until the summer rains begin. We considered this performance to be acceptable for our application.

The average rainfall at the cabin site is about $30 \%$ less than the ranch site. We determined that the existing roof surface of 28 square meters was about $25 \%$ larger than needed for optimal performance. Thus, some water would be wasted but that was not important because the collector already existed and we wanted to know whether it could supply adequate water for the cistern in our two test years.

\section{Discussion}

We procured and installed the cistern systems according to the design. We designed and constructed the collector so that it could be easily retrofitted with additional collector area, if needed. We installed trail cameras at both sites to allow us to monitor the cistern performance and use by animals. We also installed manual rain gauges to coincidently measure precipitation. We used the visual data and the logs to compare the actual performance of the cisterns to CISMOD predictions. A picture of the ranch cistern shows the final installation (Figure 3).

We have been observing the systems for over a year, starting in August of 2019. Year 2020 was among the driest years on record, similar to our dry test 


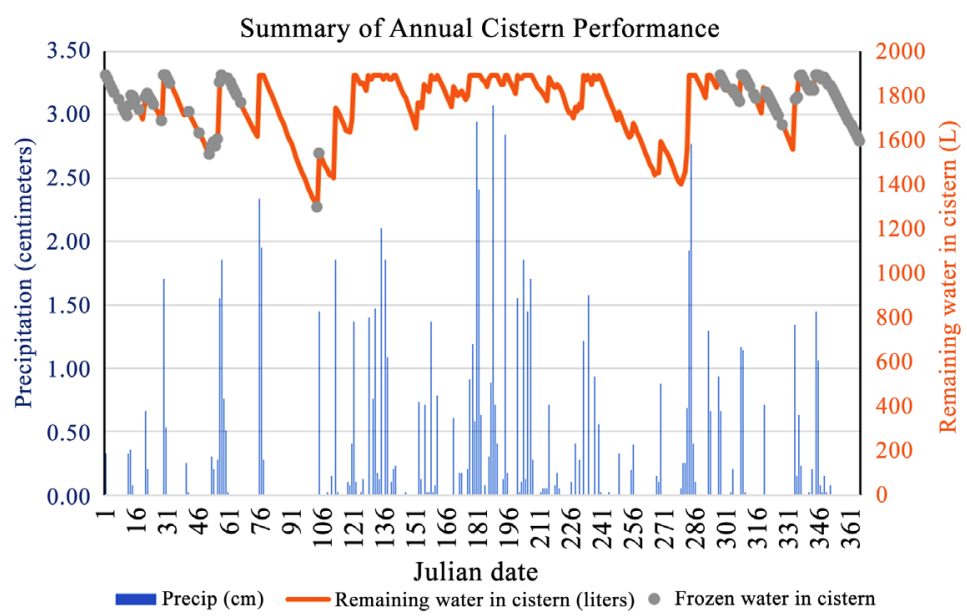

Figure 1. Simulation for the ranch cistern for 2015, best case. The numbers on the abscissa are the Julian dates. The daily precipitation totals are shown with blue bars and the water remaining in the cistern at the end of each day is shown with an orange line. The gray dots indicate days when the cistern could be frozen.

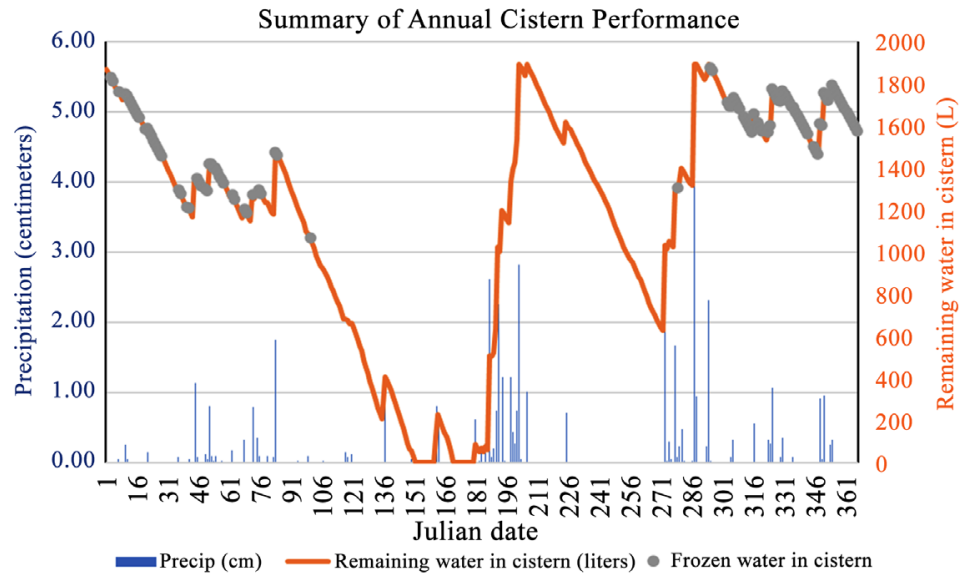

Figure 2. Simulation for the ranch cistern for 2018, worst case. The numbers on the abscissa are the Julian dates. The daily precipitation totals are shown with blue bars and the water remaining in the cistern at the end of each day is shown with an orange line. The gray dots indicate days when the cistern could be frozen.

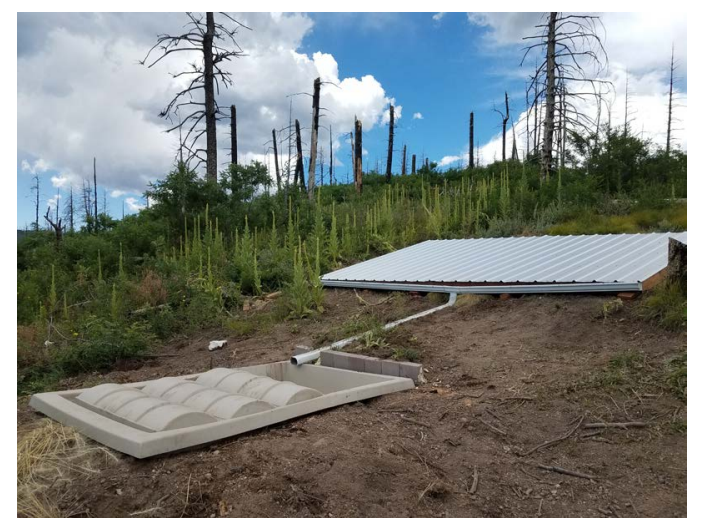

Figure 3. The final cistern installation at the ranch. The collector at far right collects rainwater and transfers it to the cistern, center of photo. 
year of 2018, so it was a good test of the design. The cistern at the ranch was fully wetted throughout the year, although its volume diminished to about $15 \%$ by early December when it froze. The amount of water remaining in the tank was within $10 \%$ of the CICMOD prediction for a dry year.

The cistern at the cabin performed as expected. The cistern remained fully wetted with nearly a full load of water even through the extreme drought period of the latter half of 2020, including a total failure of the SW Summer Monsoon, a rare event. This too was consistent with CISMOD predictions.

The trail cameras have shown that animal activity at both cisterns has been steady, with about the same numbers visiting as we had assumed. We have no quantitative measured data on visitations.

The only issue so far is cistern freezing, which prevents animals from accessing the water in the cold season. We plan to address this issue using standard engineering methods and report our findings in a future research article.

\section{Conclusions}

The use of a model, such as CISMOD, helps to facilitate the design of a complex system such as a rainwater cistern by providing insight into the performance of different candidate designs in various environmental conditions. Coupled with the application methodology we described, we used CISMOD to help us select and size the critical components used in our systems. It is available for use by others who are contemplating cistern designs. It can also be applied in other types of systems, such as tanks served by springs. The CISMOD User's Manual contains more information.

The CISMOD package is available at no cost. Weather data are the most important inputs to CISMOD and designers of cisterns in remote areas might be challenged to find appropriate data. However, there are many government and private weather datasets available that can be accessed for free. These sites are discussed in detail in the CISMOD User's Manual.

The CISMOD model and user manual can be downloaded from this site: https://www.dropbox.com/sh/2u7agwqszrfijj2/AADjXLMrA388cPelN_yxSeASa? $\underline{\mathrm{dl}=0}$

\section{Acknowledgements}

We thank the following people who aided us in this research: A. Browman, retired scientist, who shared his data with us, spending hours helping us to digitize his records. B. Parmenter, Valles Caldera National Preserve Chief Scientist, helped us to access weather data recorded at the preserve. G. McCurdy, Associate Research Scientist at the Desert Research Institute, worked with us to successfully download the Valles Caldera data. T. Sweatnam, Professor Emeritus, University of Arizona, guided us in fetching the data from his weather site. D. Trujillo, ex-Valles Caldera Executive Director, provided guidance about wild animal water usage. 


\section{Conflicts of Interest}

Neither author has any commercial or other financial interest in any of the material or devices discussed in the paper.

\section{References}

[1] Ertas, A. and Jones, J.C. (1996) The Engineering Design Process. John Wiley and Sons, New York.

[2] Hyman, B. (1998) Fundamental of Engineering Design. Prentice Hall, Hoboken, NJ.

[3] Pelak, N. and Porporato, A. (2016) Sizing a Rainwater Harvesting Cistern by Minimizing Costs. Journal of Hydrology, 541, 1340-1347.

https://doi.org/10.1016/j.jhydrol.2016.08.036

[4] Basinger, M., Montalto, F. and Lall, U. (2010) A Rainwater Harvesting System Reliability Model Based on Nonparametric Stochastic Rainwater Generator. Journal of Hydrology, 392, 105-118. https://doi.org/10.1016/j.jhydrol.2010.07.039

[5] Menicucci, D. (2021) Property and Environment Research Center. https://www.perc.org/2019/11/05/An-innovative-strategy-for-elk-management-onprivate-lands/

[6] Koppen Climatic Classification System (2021). https://en.wikipedia.org/wiki/K\%C3\%B6ppen_climate_classification

[7] The Engineering Tool Box (2019). http://www.engineeringtoolbox.com/evaporation-water-surface-d_690.html

[8] Western Regional Climate Center (2019). http://wrcc.dri.edu/vallescaldera

[9] Weather Underground service (2021). http://www.wunderground.com/dashboard/pws/KNMJEMEZ4/table/2015-02-29/20 15-02-29/monthly

[10] Dennis, T. (2019) Ex-Director Valles Caldera National Preserve, Personal Communication.

[11] Rainmaker Wildlife Products (2021). https://www.rainmakerwildlife.com/ 